\title{
REGULATORY MANAGEMENT OF DISTRESSED FINANCIAL MARKETS USING SIMULATION
}

\author{
Mark E. Paddrik \\ Gerard P. Learmonth, Sr. \\ Systems \& Information Engineering \\ University of Virginia \\ Charlottesville, VA 22904, USA
}

\begin{abstract}
Government economic policy regarding the financial markets in the United States has been focused on promoting self-regulation based on a belief in natural equilibrium. This has led to decreased regulation and permitted an increase in the complexity of financial assets that has to some degree exceeded the capability of the market to understand the fundamentals of what is being traded. This lack of understanding or information about these assets' values created liquidity problems, and contributed to the crises seen in both US and world markets. Through the use of an agent-based simulation model of an economic market, this paper looks at the effect of information on keeping the markets liquid and at potential strategies to protect markets from illiquidity failure. It considers how the three main government controlled market influences: interest rate targeting, 'information' regulation, and market making can affect market stability.
\end{abstract}

\section{INTRODUCTION}

Financial markets have repeatedly failed to stay liquid due to various market problems that have led to investors losing their ability to easily buy and sell assets. With the United States' markets coming out of the most recent recession in 2008, the same old questions of 'what caused the downturn?', and 'could it have been prevented?' were asked. While the answers as usual have become clearer, and new regulations have been passed to try to prevent the event from reoccurring; the process through which markets are fundamentally managed during times of distress still needs the attention. New theories concerning management of the 2008 deep recession will inevitably be created and lead to changes in decision making policy and regulations at the Department of Treasury, Federal Reserve, Federal Deposit Insurance Corporation, and/or the Security and Exchange Commission.

The potential effects of such organizations' regulations or decisions on markets needs to be tested. Admittedly, the options these entities have at their disposal for controlling markets are neither instantaneous nor precise. The markets are basically free in nature and are really a loose organization of single actors taking a spectrum of different actions towards the same goal of building wealth. To capture the nature and essence of an exchange market and determine what needs to be done to maintain market health, a model based on an agent-based simulation composed of multiple interacting intelligent agents can be used to test different basic strategies for preventing market failure. In particular, we will examine the problem of liquidity risk which affects market participants' ability to trade quickly and at a low cost (Paster and Stambaugh 2001). 


\section{Paddrik and Learmonth}

The market considered in this paper is the commercial paper/corporate bond market as it is a market that is easily influenced by government regulation, and, also, very simple to model versus the equities market which has a number of other factors to consider. The goal is to understand the most important rules affecting this market in the model, and then monitor its health using real data from 2004 to the end of 2009, and see the effects of different types of government interventions.

\section{BACKGROUND}

\subsection{Understanding Market Fundamentals}

In creating a model of this market, we first needed to identify a simple basis to represent the fundamental control units and rules through equations that effectively characterize the market participants and their objectives. It is important to reflect the fundamental principles that appear when looking at different types of markets, and how they relate to their transactions and institutions.

Alvin E. Roth, a Nobel laureate for his work in market design, examined the principles of numerous marketplaces within the medical community and found they all have the same principle requirements to function effectively and fairly for both doctors and patients. The first principle is 'thickness' which refers to an attractive element wherein a "sufficient proportion of potential market participants come together ready to transact with one another." (Roth 2008) The second principle is related to ways to control the congestion that thickness brings, "by providing enough time, or by making transactions fast enough, so that market participants can consider enough alternative possible transactions to arrive at satisfactory ones." (Roth 2008) The last principle concerns bringing safety to the participants through simple regulation.

When any of the foregoing three elements have risk associated to them, the likelihood of a transaction occurring is decreased, which reduces the liquidity of the market. This is not necessarily an easy thing to measure, yet it is considered one of the most important metrics of a market's health. Roth's studies point to the basis for building a model that tries to look at the market situation, and what is needed to keep it liquid, in order to prevent market failure. To do so, it is necessary to understand the best methodology to predict liquidity.

\subsection{Defining Liquidity and Measures of Information}

The liquidity of an asset tends to be defined by the difficulty to take and/or exit a position held. The liquidity in markets, however, has two popular ways of being measured. The first is related to the spread of the bid-ask prices; the larger the spread, the more illiquid the market. The second looks at the size of the market and its related neighbor markets to determine how relatively liquid a position is in that particular market versus another. In our model, we will use the second definition as our indicator of liquidity, as it allows us the flexibility to physically count the number of participants (traders and market makers) in our market.

These measures may not seem that different, until you look at how the evaluation of liquidity and returns match up. Brennan and Subrahmanyam (1996) showed a positive linear relationship when looking at US data for bid/ask spreads and prices. Jacoby and Fowler (1997) showed that, in equilibrium, a nonlinear relationship is predicted between required return and stock volume (liquidity). The relationship is first concave on the left side for liquid stocks and then convex for more illiquid stocks. Such relationships of price and volume have for quite some time been shown to be the best measures of the liquidity of an asset.

Another metric that has been considered is the free-float rate, which has been examined by Jacques Hamon and Bertrand Jacquilla. This measure considers the "adjusted shares quantity" which is the portion of the total listed shares that are deemed truly to be available for purchase in the market. In other words, it excludes so called "fixed shares" such as shares held by major shareowners. To define a risk premium and 


\section{Paddrik and Learmonth}

a liquidity premium, the authors used "a practical version of the Capital Asset Pricing Model together with financial analysts' expectations on future cash flows" for about 150 French companies traded on the Paris Bourse representing about $90 \%$ of the total French market capitalization (1997). This method proved to be a very reliable model for determining the associated liquidity premium of the stocks based on information about how much of the stock was actually actively traded.

The above concept supports the common sense fact that investors are less likely to invest in assets of which they do not have complete information on. This suggests that more disclosures (i.e. information) can make a firm's stocks and bonds more marketable and its risk evaluation allows it to be treated closer to that of cash (Lester, Postlewaite, and Wright. 2011). This leads to increased efficiency in the firm's real investment decisions and reduces a firm's cost of capital by attracting increased demand from large investors that value the increased liquidity of its securities (Baiman and Subrahmanyam 1996).

This opportunity to gain investment interest based on the belief that a company has a solid base has not been lost on business. Public firms have increased expenses on investor relations departments to provide more information to outside investors and, in turn, to improve stock liquidity (Healy and Palepu 2001). In Information Production and Market Liquidity, Chen and Park (2006) are able to "test whether the firms' efforts increased their stock liquidity. More importantly, they tested whether the effect of internally-produced information is a substitute for or a complement to the effect of analysts on stock liquidity." By looking at 275 firms from S\&P MidCap 400, they were able to show that firms with more employees working in investor relations departments achieved a significantly higher stock liquidity, and that the effect on liquidity is (more) pronounced in cases when outside information produced by analysts is not sufficient." (Chen and Park 2006) This work pointedly demonstrates how information disclosure increases a company's stock liquidity.

\subsection{Market Makers}

In general, regulations that govern information availability and clarity cannot be made and put into practice quickly enough to impact markets suddenly facing dire liquidity problems. In these cases, the US and other governments' interventions in financial markets in times of illiquidity, have been through participating in the commercial paper market to keep business capital available. They have acted in a similar manner to market makers, who are prepared to quote both a buy and a sell price for a financial instrument.

The market markers role has traditionally been to keep markets efficient, even if they do not have any net stake in the market. "The market maker can be viewed as a conduit through which money flows from liquidity- motivated transactors to transactors with special information" (Treynor 1971). In order to stay in business, the market maker must earn more from liquidity-motivated transactor than he loses to the transactor with special information. Every time one transacts against the market maker, a "spread cost" is incurred, in addition to any explicit brokerage commission.

\subsection{Use of simulation by exchanges and regulators}

Financial simulations have been used for testing markets for the last few years and have now begun to gain more acceptance by business as a legitimate form of evaluation tool. The NASDAQ, a large financial electronic exchange, first used an agent based simulation environment to test trading strategies used by market-makers and investors and gauge, market participants' interactions to understand the impact of new rules and regulations on price tick size (Darley and Outkin 2007). Hayes et al. (2013) similarly examined the impact of new regulations on minimum quote life through simulation experimentation which generated trade-off curves to inform the associated financial policy debate. The opportunity help build understanding in the policy and decision space of complex systems like financial markets is fertile for new simulation developments. 


\section{Paddrik and Learmonth}

\section{MODEL DESIGN}

An agent-based simulation model was developed to describe commercial paper / corporate bond market in Netlogo (Wilensky 1999). This market is essential for large companies to borrow from banks and other corporations and is viewed to be a market over which the government has clear influence, as seen by the United States Federal Reserve entrance to this market in October, 2008 with the creation of the Commercial Paper Funding Facility. This market is a much simpler market to model versus the equities market which has a number of other factors to consider due to the effects of more speculation. The goal for this paper's simulation of the commercial paper / corporate bond market is to identify the most important rules of this market in the model, and, then, monitor its health using real data from 2004 to the end of 2009.

For simplification and data purposes, the model developed used three sectors of market: financial (blue), utilities (green), and energy (red) (see Figure 1). Additionally each sector was deemed to have three levels of risk, low, medium, and high, associated with realizing returns from assets; giving the model, in effect, a total of nine types of assets. For each of these types of assets, we collected prices and coupon/dividend payment data publicly available for preferred stocks, which mimic the bond market. Using the time series of real price returns and coupon payments between 2004 and 2009 from the preferred stocks, we created roughly 300 simulated corporate bonds for each of the nine classes of bonds, with varying asset prices and dividends which tracked the real data.

The bonds, represented as "patches" in Netlogo, are placed in the groupings shown in Figure 1 such that 300 patches represent the 300 distinct bonds that are contained in a colored sector/risk level region. It is important to note that Figure 1 is a simplified representation of a continuous surface having an infinite horizons such that each sector grouping has a Moore Neighborhood with each of the other eight bond classes bordering it.

Within this representation of the market of bonds, the bonds are located such that the shorter the distance that between two bond patches, the more closely they are understood to be related to one another (i.e. their underlying companies/business areas share more common features). For potential investors, this means they have more information about bonds that are closer to bonds that they currently own such that they are better informed as to how to evaluate the bonds surrounding the one they currently own.

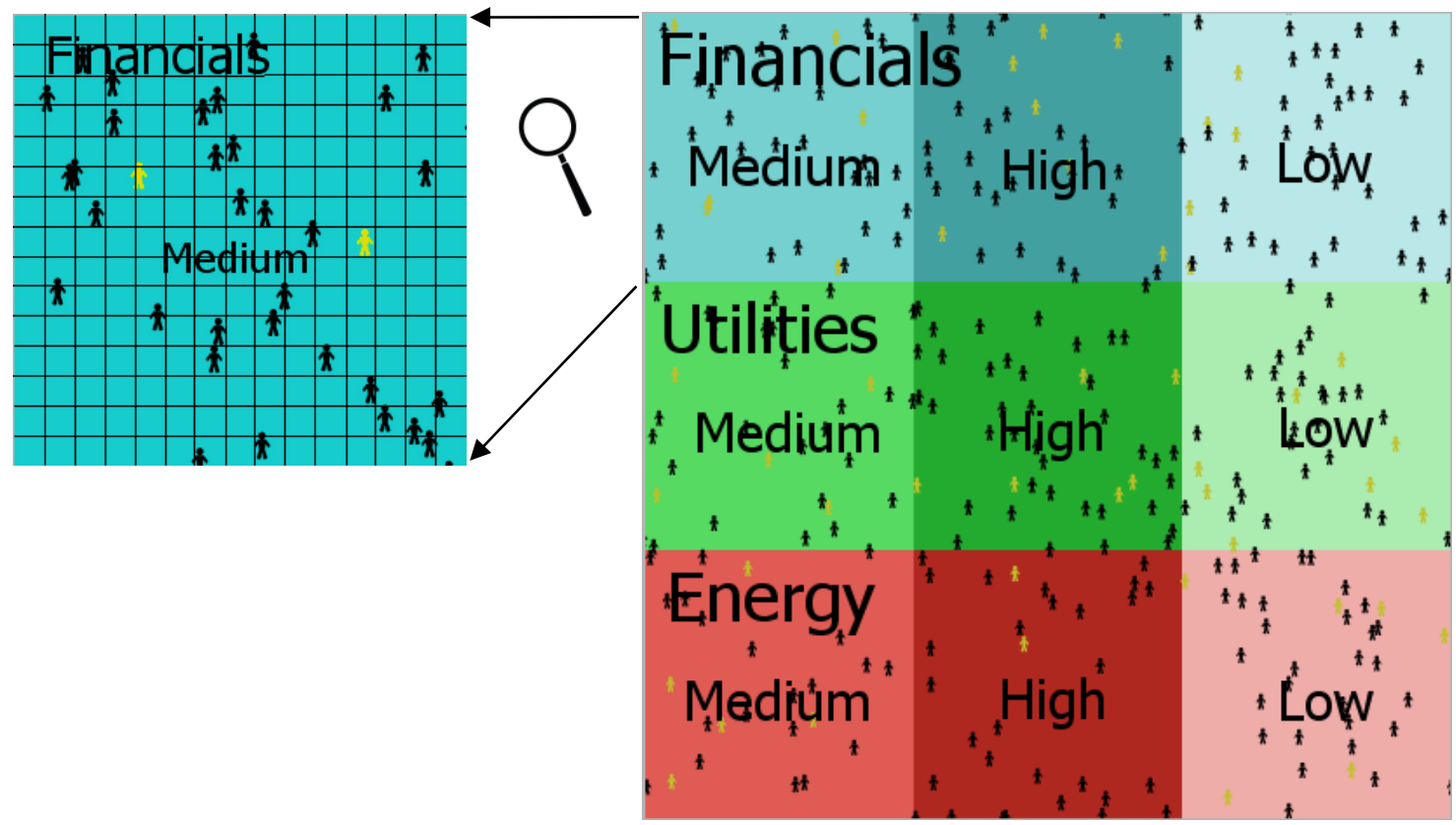

Figure 1: Visual representation of the corporate bond market. 


\section{Paddrik and Learmonth}

The model used two types of investor agents, Traders and Market Makers. The Trader, represented by black human shaped figures in Figure 1, must evaluate if it is worth entering the simulated bond market or hold their capital in a safe the risk free asset, like a US Treasury note, which earns the Federal Funds Rate. Traders are willing to enter the bond market when they see that the average return on their capital for bonds, which is the average annualized coupon payment of a bond divided by its price, is higher than for the Treasury notes. Figure 2 shows the average rate of return of the financial sector bonds.

If a Trader sees that the bond market is returning a better rate than the federal funds rate, they can borrow the money to buy a bond. The rate at which they can borrow is the Corporate Paper Rate, which is determined by the risk of corporate default in comparison to the Federal Funds Rate. Using the Corporate Paper Rate based on the real rate corresponding to the 2004 to 2009 time-series the Traders can evaluate if they can make money by earning the difference between the corporate interest rate and the rate of return the bond is paying them. The Trader then selects the most profitable asset from the available set of bonds such that no other Trader currently owns it. Once they select a bond to own they move to the coordinates of that bonds location on the two dimension grid.

The second agents in the market are the Market Makers, represented by black human shaped figures in Figure 1, whose job is to specialize in a market sector and provide liquidity, but at a premium to a trader who is trying to get into or out of an asset.

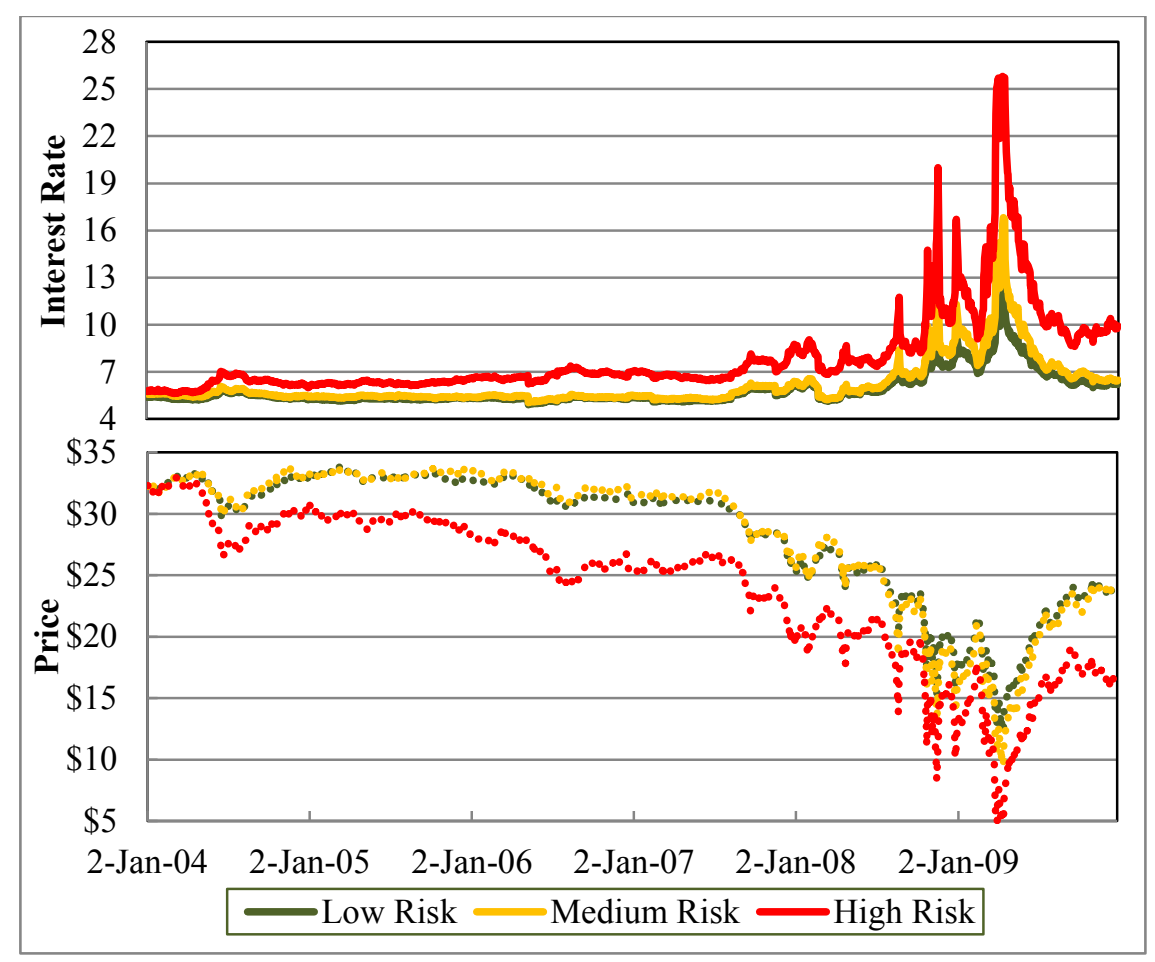

Figure 2: The market price movement in the financial sector and its influence on returns between 2004 and 2009.

During each time period in the model, the market returns of the bonds fluctuate and each asset's price and return changes according to its sector and risk level. If the bond a Trader owns is not the giving them the best return within a radius of their current positions (or even worst it is not making a positive return for them) they can trade it for another one, at cost, in hopes of finding to an asset with a greater return. Once they find one that meets this rule they will hold this asset until another bond appears to be getting a better 


\section{Paddrik and Learmonth}

relative return.

Trading, however, has two variables associated with it: the 'Liquidity Factor', the ability to find someone willing to be a counter party in the trade, and the transaction cost, the amount of cash spent to complete a trade in that market. The Liquidity Factor is modeled by whether there is someone within a radius length from the trader with whom he can trade. This radius length is determined by the amount of information a trader has at their disposal to allow other Traders to see the quality of their asset. The theory being that with more "Information" or transparency in the asset, the better chance someone will be willing to buy that asset.

The trading cost is a function of who within the information radius can trade. If there is another trader within the radius, the cost is at the Trader Premium rate that a broker would charge. If there are no traders, but there is a Market Maker, they can trade with the Market Maker. The trader will be forced to pay a higher transaction fee because the Market Maker charges a premium for its service. This is meant to simulate what happens with the bid-ask spread mentioned earlier that occurs with illiquid assets, where the spread widens and causing the sell to larger losses in a trade. If there are no other Traders with whom to trade, the Trader is forced to take a loss of the difference between the interest rate and the current asset rate. (See Figure 3)
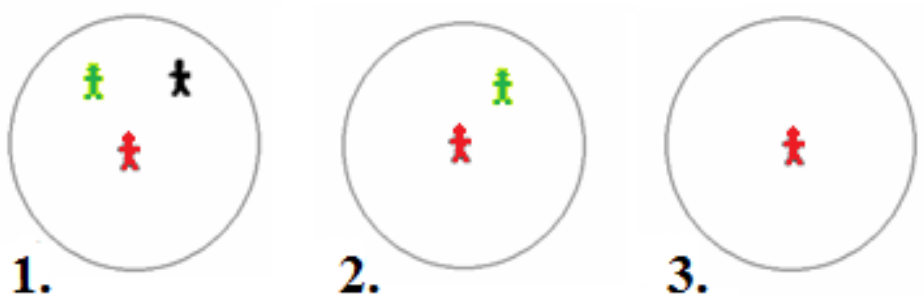

Figure 3: The trading radius (grey circles) depict three situations an individual Trader (red) might encounter when trying to make a trade: 1) At least one other Trader (black) (in the radius (note- Trader Premium will always be less than via a Market Maker.) 2) At least one Market Maker (green) and no Trader. 3) No Traders or Market Makers in radius.

We should also mention that the traders' operating accounts (i.e. where their own funds is kept) are where interest is collected or subtracted and from which transaction costs are paid. In addition, a margin requirement ( $10 \%$ for our simulations) is used and mark-to-market to account for price changes of the bonds.

The Trader can continue to trade and stay in this market until they run out of money in their operating accounts. Running out of money is a sign that the trader would have been better off keeping his money in a bank that will give them the Federal Funds Rate. Once out, the trader will not re-enter back into the market from his safe position until a bond type average market can generate better returns than the risk free rate, over a 30 day period. This is a signal to traders on the sidelines that the market is worth reentering.

\section{MARKET REGULATORY CONTROL DIMENSIONS}

In principle, financial markets are meant to find their own theoretical equilibrium prices through the freemarket system, wherein market agents determine price by trading with one another with as little government influence as possible. Unfortunately, the markets seem to need adjustment and reassurance from the government in times of turmoil, to keep liquidity sound. The three tools that the government has to help manage markets systems are information regulations, interest rate targets, and market making. These three tools have been the "knobs" for tuning markets that have been commonly used by government agencies to help stabilize markets. 


\section{Paddrik and Learmonth}

Regulation is the key to allowing Traders to trust markets. It provides a set of regulations and guidelines that ensure the information and the rules necessary to judge assets, complete transactions, and establish asset allocation strategies are in place. This control knob is, however, difficult to change quickly because of all the human interactions (i.e. red tape) that come with defining and implementing new regulations.

Interest rates are what a borrower pays for the use of money and what lenders receive for the use of funds loaned to the borrower. Managing interest rate is key to a government's monetary policy for growth, employment, and new capital creation. This can occur most readily when borrowing at low rates is used to create new productive sources of income within the economy. In the US, the Federal Funds Rate, is the targeted rate that the government attempts to manage through the Federal Reserve.

Control of interest rates has been the favored tool that governments have used to help markets recapitalize for two basic reasons. The first is that interest rates are very easy to change and changing is not very politically controversial. The second is that offering money to invest at lower borrowing rates increases spending in the economy; this acts as a counter to recessionary tendencies of savings and removing capital from markets which makes them less liquid.

Market making is seen as the most unpleasant tool for a government to use. Market making by the government is seen as spending money unnecessarily to bail-out private entities that have made bad business decisions. In some illiquid markets, private companies can provide this service. For example, the electric power sector often engages private market makers to provide liquidity (at a some premium) to ensure the viability of market agents in remote locations having very few, if any, trading counter parties. This can occur when the electricity market served is small and remote.

With these three tools in mind, the agent based simulation market model developed was used to test their relative effectiveness at influencing market behavior under different market conditions. The objective was to see which tools are better at keeping a market thriving during times of high market turbulence and overall economic down turn. In running the simulation, we assumed that the Traders and Market Makers we homogenous such that Traders had equal amounts starting capital and equal trading radius, and Market makers had equal trading costs.

\section{RESULTS}

As mentioned earlier, the agent based simulation model developed was made to demonstrate how government action can affect the health of the market. The performance indicator of the health of the market chosen was the saturation of traders in the market (i.e. the percent of all traders that the market can support in active trading measured over the lifespan of the market). This rate gives a measure of both the liquidity, by how many traders are in the market to trade with, and sustainability of the market, the ability to market of sustain traders profits in order to keep them in the market.

Using the available market adjustment dimensions, we created three different degrees of action the government could use for each of the three dimensions. The first set of these was testing the influence of commercial paper interest rates by using the original federal funds rate data with, maximum and minimum limits put on the rates. The three cases created were 1) Rates never were allowed to go over $4.5 \%, 2$ ) Rates were never allowed to go below $0.5 \%$, and 3 ) Rates had were held between $0.5-4.5 \%$. These where then compared to the base case of doing the same thing. 


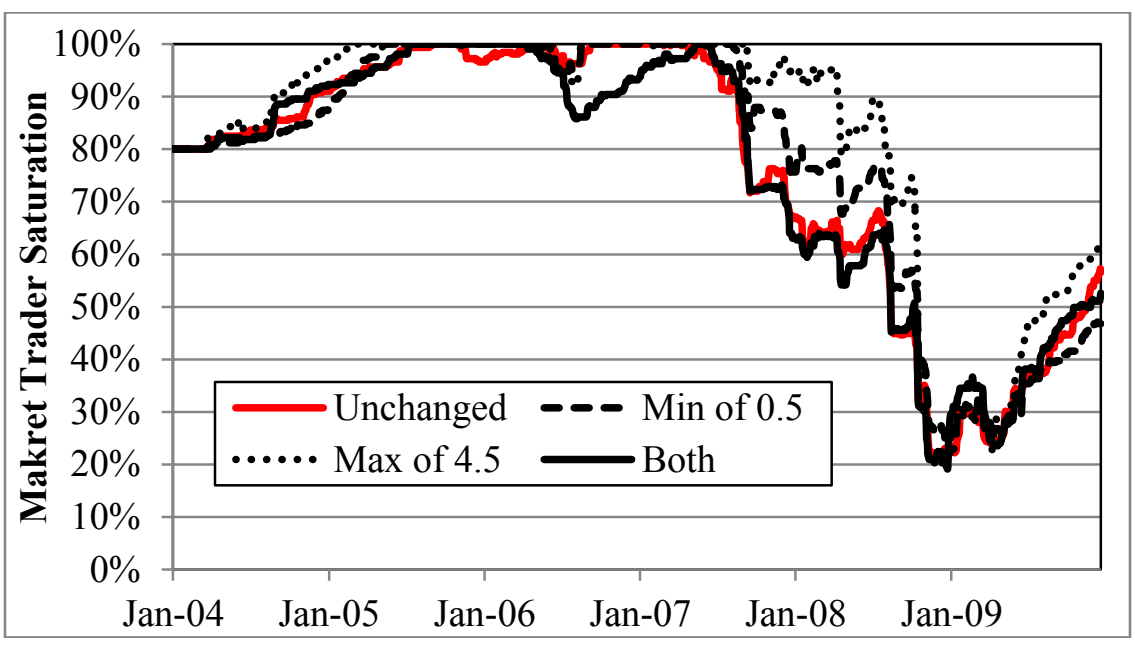

Figure 4: The effect of corporate interest rates changes on the saturation of Traders willing to hold assets.

This manipulation of the interest rates had some effects in early 2008 by allowing traders to stay in the market longer in both case 1 and 2, but provided no real help in preventing the illiquidity crisis in October of 2008 (refer Figure 4). This outcome is not too surprising since low interest rates make making money easier.

The second set of cases we examined involved the use of government regulation to increase transparency by requiring more information to be available about the liabilities of a company such that it is easier to evaluate the value of an asset. To account for more or less regulation, we adjust the radius of information a trader has or, in simpler terms, the number of bonds whose value is understood that a trader can access. This also provides more information about the bonds a trader currently owns, and, thereby, enables the trader to sell their bonds with greater ease and make the transaction less costly. The cases created were a low, medium, and high information case (the more information the larger the radius).

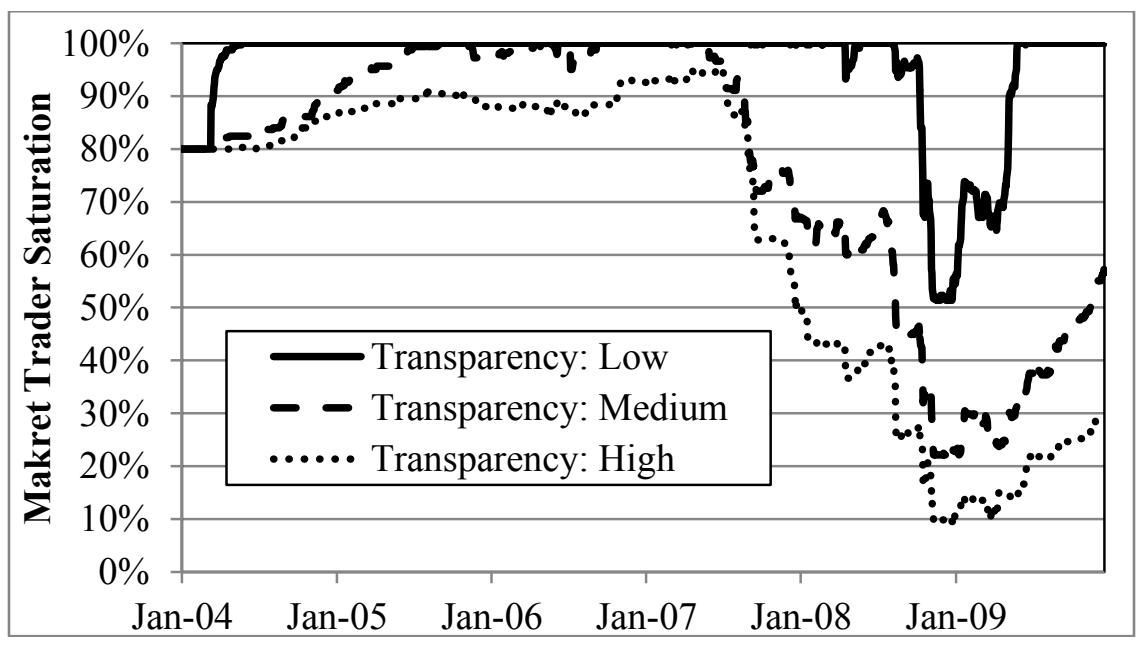

Figure 5: The effect of information transparency on the saturation of traders willing to hold assets.

The results of these cases were a rather shocking, as more transparency was given to the traders, they were less willing to enter the market and the were forced out of the market earlier (Figure 5). An interesting feature of this result was that while the saturation rate got considerably lower as the transparency was 


\section{Paddrik and Learmonth}

increased, the $t$ net earnings of the traders at any given point in time for each of the three cases were nearly equivalent.

Considering that increased transparency should have a strong fundamental positive effect on liquidity (as well as efficiency of bond selection) by increasing the Roth's market thickness feature, it is hard to believe that more traders were able to exist in a lower transparency market. However, when we look at a secondary effect of increased transparency and market efficiency, we can see an unintended consequence that occurs in these markets: an increased flocking effect by Traders to the sector or bond class that is currently achieving the highest the overall returns at the time. This creates small 'boom and bust cycles' due to the over saturation of traders into single bond type which can then experience a sector down turn, and, in turn, cause some traders to lose all their money very quickly and bust.

In contrast, the low transparency market seems to lead to a visibly more saturated market, but it does, however, seem to result in very sudden drops and recoveries in markets saturation. This feature of "reaching a critical point of in the system" (Rogers et al. 2005) does give concern that, though the saturation rate was better, the points of inflection may not be good for supporting the longevity and success of the economic system.

The last of the components we looked at was the effect of the government or Federal Reserve entering enter the market and acting as agent or 'Market Maker'. The three cases we looked at were the effect of having 25, 50, and 100 Market Makers in the market providing liquidity to Trader (see Figure 6).

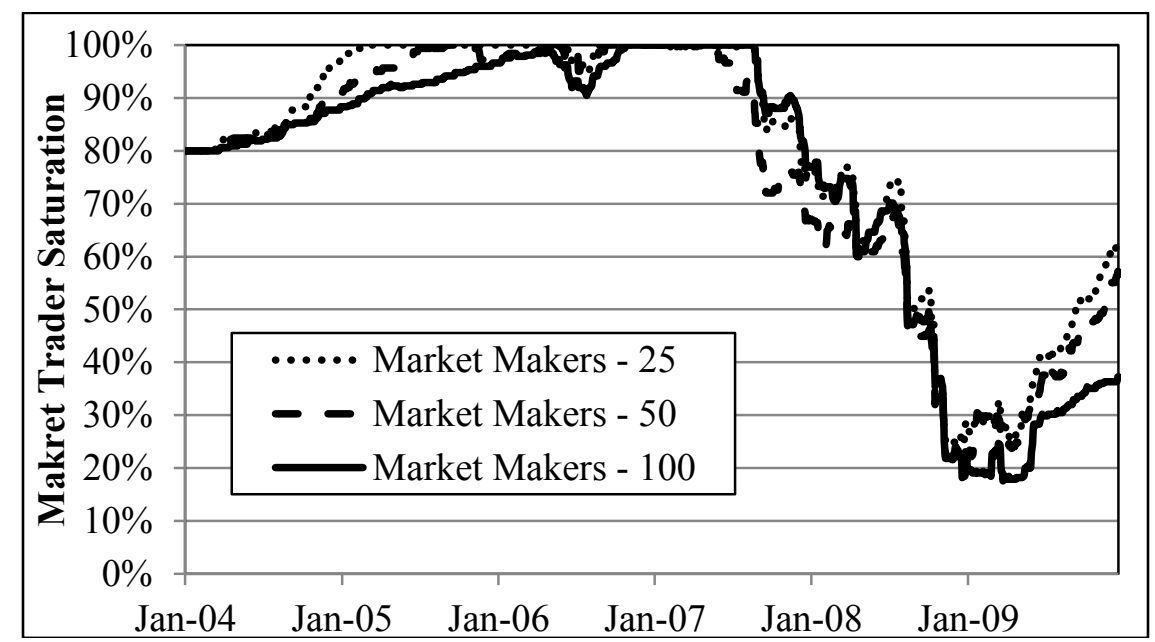

Figure 6: The effect of Market Makers on the saturation of Traders willing to hold assets.

The results of these cases showed that increased Market Makers presence did not have a significant effect to help liquidity and prevent Trader exit from the market. This is not to say, though, that the government acting as a buyer of bonds for the short term is not required to prevent companies from entering bankruptcy quickly due inability to get loans, but careful analysis of the decrease in liquidity must be understood or it could be a costly proposition for the government if any of the assets do go to zero. The simulation also showed a counter intuitive result during recovery, that the Market Maker can impede Traders desire to re-enter the market because Market Makers can make it too costly to enter the market because of high transaction costs.

\section{CONCLUSION}

The work underlying this paper demonstrates that agent-based simulation models can be developed to mimic a market's reaction to a government's initiatives to influence and stabilize markets. The model helps test and understand the relative impact and effectiveness that the tools available to government enti- 


\section{Paddrik and Learmonth}

ties. The model's results are very relevant to aiding the development of an understanding of the effectiveness of measures governments are currently taking to counter the recent failure of financial markets which was rooted in illiquidity issues.

This study was able to demonstrate that the tools the government regularly uses can have different impacts in different market situations and suggested some very interesting outcomes that we had not expected. The largest of these being the almost counter intuitive negative effect of increased transparency on a market causing a drop in the number of market participants. This suggests that increase liquidity from information can cause flocking between sectors to what is considered the 'hot sectors'.

During the 2007-2008 financial crisis, there was a sudden recognition of the lack of information and regulation in the mortgage based securities market which caused traders to quickly leave this market sector. It may not necessarily be the fundamental cause of the crisis, but it was likely to have been a driver for the earlier over investment seen in that sector.

Even though the study did not show large effects from the other two government management dimensions, it does not mean that the government should not focus its efforts on using them most effectively. However, as seen in the model, perhaps they should be limited as they can cause secondary effects.

Finally, though the model may not be a precise depiction of the true financial market and what participants would actually do, it does allow us to think through different scenarios and outcomes that may not be expected. Agent-based models like these can help regulators the ability to "think outside of the box" of traditional economics and finance and consider systemic issues not easily visible in market data.

\section{REFERENCES}

Baiman, S., and R. Verrecchia. 1996. "The Relation Among Capital Markets, Financial Disclosure, Production Efficiency, and Insider Trading." Journal of Accounting Research 34(1):1-22.

Brennan, M. J., and A. Subrahmanyam. 1996. "Market Microstructure and Asset Pricing: on the Compensation for Illiquidity in Stock Returns." Journal of Financial Economics 41(3):441-464.

Chen, C., and J. Park. 2006. "Information Production and Market Liquidity." Working Paper. University of South Florida .

Darley, V., and A. Outkin. 2007. A NASDAQ Market Simulation: Insights on a Major Market from the Science of Complex Adaptive Systems. Singapore: World Scientific Publishing Co.

Hamon, J., and B. Jacquillat. 1999. "Is There Value-added Information in Liquidity and Risk Premiums?" European Financial Management 5(3):369-393.

Hayes, R., M. Paddrik, A. Todd, S. Yang, P. Beling, and W. Scherer. 2012. "Agent Based Model of the EMini S\&P 500 Future: Application for Policy Making." In Proceedings of the 2012 Winter Simulation Conference, edited by C. Laroque, J. Himmelspach, R. Pasupathy, O. Rose, and A. M Uhrmacher. Piscataway, New Jersey: Institute of Electrical and Electronics Engineers, Inc.

Healy, P., and K. Palepu. 2001. "Information Asymmetry, Corporate Disclosure, and the Capital Markets: A Review of the Empirical Disclosure Literature." Journal of Accounting and Economics 31(1):405440.

Héritier, A. 1997. "Market-making Policy in Europe: Its Impact on Member State Policies. The Case of Road Haulage in Britain, the Netherlands, Germany and Italy." Journal of European Public Policy 4(4):539-555.

Jacoby, G. and , D. J. Fowler. 1997. "The Capital Asset Pricing Model and the Liquidity Effect: a Theoretical Approach." Journal of Finance 52(4):1355-1382.

Lester, B., A. Postlewaite, and R. Wright. 2011. "Information and Liquidity." Journal of Money, Credit and Banking 43(2):355-377.

Pastor, L., and R. Stambaugh. 2003. "Liquidity Risk and Expected Stock Returns." Journal of Political Economy 111(3):642-685. 


\section{Paddrik and Learmonth}

Rogers, E., U. Medina, M. Rivera, M., and C. Wiley. 2005. Complex Adaptive Systems and the Diffusion of Innovations. The Innovation Journal: The Public Sector Innovation Journal 10(3):1-26.

Roth, A. 2008. "What Have We Learned from Market Design?" The Economic Journal 118:285-310.

Treynor, J. 1995 "The Only Game in Town." Financial Analytics Journal 51(1):168-171.

Wilensky, U. 1999. NetLogo. http://ccl.northwestern.edu/netlogo/. Center for Connected Learning and Computer-Based Modeling, Northwestern University. Evanston, IL.

\section{AUTHOR BIOGRAPHIES}

MARK E. PADDRIK is a PhD Candidate with a MS and BS in System Engineering, and BA in Economics from the University of Virginia. He has done work in time series forecasting in US equities and futures for risk management for Pace Global Energy and ARC. A few papers that are related to this work include Agent Based Model of the E-MINI Future Market: Applied to Policy Decisions, Indicators for Price Discovery Anomalies, and The Market Echo Chamber: Intermediation in Financial Markets. His current interests lay in the use of agent-based simulation for policy decision making in finance and health care. He works with the Commodities and Futures Trading Commission to help detect and prevent manipulative trading practices. With the UVA hospital he is helping to investigate how to prevent the creation and spread of drug-resistant bacteria. His email address ismp3ua@virginia.edu.

GERARD P. LEARMONTH, SR. is a Research Associate Professor in the Department of Systems and Information Engineering, University of Virginia. He received the B.S. and M.B.A degrees from New York University, an M.S degree in operations research from the Naval Postgraduate School, and a Ph.D. degree in statistics and management science from the University of Michigan, Ann Arbor. He holds a secondary appointment as Associate Professor in the Department of Public Health Sciences in the School of Medicine. His current research projects include: the continued development of participatory simulation focused on sustainability of the Chesapeake Bay Watershed - the UVa Bay Game; and an agent-based simulation model to assess the efficacy of planned water and sanitation interventions to improve the longterm health and growth of children in Limpopo Province, South Africa. His email address is j15c@virginia.edu. 